\title{
O (O)CASO \\ DO VOSEIO \\ PORTUGUÊS \\ DO NORDESTE \\ TRASMONTANO
}

EL DECLIVE DEL VOSEO PORTUGUÉS EN EL NORESTE DE TRÁS-OS-MONTES

THE DECLINE OF PORTUGUESE VOSEO IN NORTHEAST TRÁS-OS-MONTES

Manuel Duarte João Pires*

Universidade de Sun Yat-sen | Universidade de Lisboa

RESUMO: O voseio vós-tu, uso do pronome vós para referir a segunda pessoa do singular, forma de tratamento peculiar e reverente em alguns locais do Nordeste Transmontano, tem vindo a desaparecer ao longo das últimas décadas. O presente estudo tem como objectivo analisar o uso deste voseio numa aldeia raiana da referida região geográfica através de entrevistas a indivíduos de diferentes grupos etários. Este estudo conclui que atendendo às mudanças de cariz sociocultural è à idade de quem muito pontualmente ainda faz uso desta forma de tratamento (as gerações mais seniores), o voseio do Nordeste Trasmontano, embora ainda se use, deverá desaparecer por completo a breve prazo. O ocaso deste voseio deixa a língua portuguesa e o Nordeste Trasmontano, em particular, despojados de uma das suas várias e cadentes particularidades sociolinguísticas.

PALAVRAS-CHAVE: Voseio. português. Nordeste trasmontano. Mudança social e linguística.

RESUMEN: El voseo vós-tu, el uso del pronombre vós para referirse a la segunda persona del singular, una forma de trato peculiar y reverente de las tierras del noreste de Trás-os-Montes (Portugal), ha ido desapareciendo en las últimas décadas. El presente estudio analiza el uso del voseo en un pueblo rayano en la región geográfica antes mencionada a través de entrevistas con personas de diferentes grupos de edad. Este estudio concluye que a la vista de los cambios socioculturales y de la edad de quienes muy ocasionalmente todavía utilizan esta forma de tratamiento (las generaciones mayores), el voseo del noreste transmontano, aunque todavía se usa, debería desaparecer por completo a corto plazo. Este declive en el voseo deja a la lengua portuguesa y al noreste transmontano en particular despojados de una de sus muchas y declinantes particularidades sociolingüísticas.

PALABRAS CLAVE: Voseo. Portugués. Noreste transmontano. Cambio social y lingüístico.

ABSTRACT: The voseo vós-tu, the use of the pronoun vós to refer to the second person of singular, a form of peculiar and reverent treatment in the lands of the northeast Trás-os-Montes (Portugal), has been disappearing over the last decades. This study analyzes the use of voseo in a border village of the aforementioned geographical region through interviews with people of different age groups. This study concludes that in view of the sociocultural changes and the age of those who occasionally still use this form of treatment

* Leitor de Português na Universidade de Sun Yat-sen (China). Doutorando em Estudos Portugueses (Universidade de Lisboa). E-mail: 
(the eldest generation), the voseo of northeast Trás-os-Montes should disappear completely in the short term. This decline leaves the Portuguese language and the Northeast Trás-os-Montes region deprived of another of its overtaken sociolinguistic particularities.

KEYWORDS: Voseo. Portuguese. Northeast Trás-os-Montes. social and linguistic change.

\section{INTRODUÇÃO}

No âmbito dos conceitos de mudança linguística, entendida como a evolução que qualquer língua regista ao longo da sua história e às transformações que sofre devido a razões de natureza social, econômica, política, geográfica e cultural que moldam a língua ao longo dos tempos (MATEUS, 2003) e, principalmente, de mudança social que integre as formas de tratamento "no quadro das transformações sociais e culturais que se têm vindo a operar em Portugal" (GOUVEIA, 2008, p. 97), o presente estudo analisa a recorrência do voseio na língua portuguesa, especificamente o voseio vós-tu, próprio de algumas localidades do Nordeste Trasmontanto, como é o caso da aldeia de Avelanoso onde esta investigação teve lugar. Esta aldeia do distrito de Bragança situa-se junto da raia com Espanha de um lado e do limite do concelho de Vimioso (ao qual pertence) com o de Miranda do Douro, do outro, tendo como localidades mais próximas algumas aldeias do lado espanhol e a aldeia mirandesa de São Martinho de Agueira. Trata-se de uma aldeia e de uma área geográfica com características sociais e linguísticas muito próprias onde convivem desde há muito, as línguas portuguesa, mirandesa e espanhola e onde existem vários elos e intercâmbios entre elas por vezes difíceis de descortinar. Um dos aspectos sociolinguísticos singulares desta localidade é o uso do voseio vós-tu entre pessoas de diferentes faixas etárias nas relações de família ou proximidade. Nesta forma de tratamento as pessoas mais novas utilizam o pronome vós quando se dirigem às gerações mais velhas e estas retorquem com o pronome $t u$. Refira-se que este voseio utiliza um pronome da $2^{\mathrm{a}}$ pessoa do plural (vós) para referir a segunda pessoa do singular, pois é dirigido a uma só pessoa. Nesta medida, consiste numa forma híbrida porque designa diferentes pessoas do ponto de vista discursivo (segunda do singular) e do ponto de vista gramatical (segunda do plural), à imagem do pronome você que também é híbrido na relação entre discurso e gramática, pois "a pessoa a quem se fala é a segunda, mas leva o verbo para a terceira pessoa" (CINTRA; CUNHA, 2002, p. 292).

Este trabalho defende que o voseio na aldeia de Avelanoso chegou até aos dias de hoje por via da língua portuguesa, uma vez que "a referência do pronome vós a uma só pessoa era normal como tratamento de cerimónia em português antigo e clássico” (CUNHA; CINTRA, 2002, p. 287). No entanto, também há teorias que podem sugerir uma aproximação à língua mirandesa. Segundo Ferreira $(1995,2008)$ um dos traços distintivos do mirandês é precisamente a "utilização de vós como forma de tratamento respeitosa (ex.: "Bós adonde ides, tiu Fracisco?)" (FERREIRA, 2008, p. 122). Existem, inclusive, estudos que apontam para o fato de esta ter sido uma aldeia onde anteriormente se poderia ter falado mirandês:

[...] o Mirandês ocupava uma área mais vasta: por volta de 1967 ainda se falava o mirandês na aldeia de Caçarelhos, no concelho de Vimioso e há mais tempo falava-se, nesse mesmo concelho, nas aldeias de Avelanoso, São Joanico, Vila Chã da Ribeira, Serapicos e Campo de Víboras. (MOURINHO, 1987 apud FERREIRA, 2008, p. 123)

Não é de excluir ainda que este voseio constitua uma marca dos diversos dialetos asturo-leoneses dos quais o mirandês se formou (ELIZAINCÍN, 2006; FERREIRA, 2004) e que abrangiam a área geográfica do Nordeste Trasmontano. Está igualmente por estudar se o próprio voseio mirandês provirá do português antigo ou do espanhol antigo, levado para as Américas no século XV (CARRIBURO, 1997).

Por entre as dúvidas que as várias hipóteses levantam, fica a certeza de que é uma forma de tratamento única na língua portuguesa e amplamente desconhecida pelos seus falantes. Também os estudos linguísticos omitem este voseio, inclusive algumas obras de referência. A Nova Gramática do Português Contemporâneo de Cunha e Cintra (2002) diz em relação ao uso do pronome vós, para referir a uma só pessoa, "empregar-se uma vez por outra, em linguagem literária de tom arcaizante para expressar distância, apreço social", tendo sido por muito tempo usado por católicos portugueses e brasileiros como forma de se dirigirem a Deus, prevalecendo o seu uso ainda nos dias de hoje (p. 287-288). De igual modo, Teyssier (1997) em História da Língua Portuguesa afirma que "desde 
o século XIX a segunda pessoa do plural sai completamente do uso falado" (p. 60), assim como Biderman (1972) que é igualmente elucidativa na sua obra Formas de tratamento e estruturas sociais: "vós desapareceu de todas essas sociedades, conservando-se, enquanto forma, apenas na Argentina (p. 373)."

A verdade é que vós não desapareceu e ainda não saiu completamente. $\mathrm{O}$ voseio português sempre viveu entre nós durante todo este tempo, despercebido entre as gentes raianas da terra fria trasmontana.

Com o intuito de trazer à luz esta forma de tratamento e de compreender melhor a sua recorrência e vitalidade na atualidade, esta pesquisa baseou-se no método de entrevistas, realizadas a indivíduos de diferentes categorias etárias da referida localidade. Num momento em que o voseio do português se desvanece, o presente estudo tem o propósito de registar e analisar a sua ocorrência, mas principalmente o de destacar e celebrar a sua vivência ímpar e identitária na língua portuguesa e nas interações comunitárias do Nordeste Trasmontano.

\section{DE ONDE VINDES VÓS?}

Apesar de não ser objetivo principal deste estudo efetuar uma análise diacrónica sobre a origem do pronome vós enquanto forma de tratamento da língua portuguesa ou sobre a evolução do seu uso ao longo dos séculos, este ponto do trabalho apresenta uma breve perspetiva sobre essa temática.

Segundo Cintra (1972) há registos do pronome vós, utilizado como única forma de cortesia, desde o português antigo até ao século XIV. A partir dos séculos XV e XVI começam a surgir as formas de tratamento iniciadas pelo pronome possessivo do género feminino, vossa. Estas formas ao invés de requererem a $2^{\mathrm{a}}$ pessoa do plural, exigem a $3^{\mathrm{a}}$ pessoa do singular, introduzindo maior distanciamento, são os casos de vossa mercê, vossa senhoria, e posteriormente, vossa majestade ou vossa alteza. O pronome vós coexistiu como principal forma de cortesia dirigida aos reis, durante algum tempo, até que em 1597 Dom Filipe II instituiu em Portugal as "leis das cortesias" que estabeleciam os limites do emprego de cada tratamento e "fixavam as penas em que incorriam os que exigissem para si próprios uma fórmula que lhe não fosse adequada segundo este texto legal” (p. 24). Estas leis tiveram duas consequências a destacar: primeiro suscitaram uma corrida aos títulos, ou seja, qualquer nobre, ou menos nobre, pretendia reclamar para si determinada forma de tratamento em busca do prestígio que significavam. Outra consequência, foi o fato de o pronome vós perder importância no plano da cortesia, deixando de ser utilizado no tratamento para os estratos mais altos da sociedade e difundindo-se entre as classes mais baixas. Nas obras de Teyssier (1997, p.60), segundo o qual "[...] até por volta de 1500, o português conhecia, como o francês, apenas o tuteamento familiar ou o voseamento respeitoso", ou de Biderman (1972) podem-se encontrar argumentos semelhantes sobre a evolução da forma como os falantes se dirigiam ao seus interlocutores em português.

Para Biderman (1972, p.341) “[...] toda a sociedade diferenciada em classes, insiste em cultivar uma etiqueta que individualize a elite da massa" estando a assimetria que o poder origina, claramente indicada pela forma de tratamento utilizada. Enquanto nas sociedades fortemente hierarquizadas do passado, o poder era a força dominante das formas de relações sociais, hoje em dia estas regem-se pela solidariedade, prevalecendo o sentimento de interdependência e igualdade entre cidadãos com interesses e responsabilidades recíprocos. Esta concepção democrática das relações sociais contrasta com a disparidade que se vivia no tempo da monarquia em que as formas de tratamento significavam prestígio. A nobreza aumentava os títulos e estes espalhavam-se a mais pessoas, levando os reis e altos nobres a criar formas de tratamento cada vez mais exclusivas, como é o caso de Alteza ou Majestade em desabono de Mercê ou Senhoria, pois quando os nobres começaram a usurpar os títulos aos monarcas estes começaram a "reivindicar outros que se lhes aplicasse privativamente" (p. 343). Biderman argumenta que foi a Revolução Francesa e os seus ideais igualitários que plantaram "a semente da solidariedade universal" que cresceu no século XXI (p. 342).

Os estudos de Brown e Gilman (1960, p.257) falam também no binômio semântica do poder e semântica da solidariedade para se referirem às mudanças de paradigma nas formas de tratamento. A semântica do poder está ligada a não reciprocidade das hierarquias, enquanto a semântica da solidariedade surge associada a uma interação igualitária que promove tratamentos recíprocos mesmo entre indivíduos de diferentes classes sociais e hierárquicas (BROWN; GILMAN, 1960, p. 258). 
Em síntese, a literatura sobre o tema revela que o pronome vós começou a perder estatuto desde que a alta nobreza e as hierarquias superiores se começaram a referir aos seus subalternos por $t u$ como forma de vincar a superioridade e o poder, promovendo a distância e a não reciprocidade de outras formas de tratamento subsequentes. O valor social de vós esbateu-se e passou então a ser de uso mais comum entre as classes mais baixas. Segundo Biderman (1972, p.366), um percurso idêntico aconteceu também no espanhol, em que o uso de vós esmoreceu na península, mas se disseminou fortemente pela América Latina, "por certo colonizada pela classe baixa da Península Ibérica", num fenômeno que se costuma chamar de "voseo".

A presença do voseio na América hispânica será abordada de forma mais aprofundada no ponto seguinte deste trabalho.

\section{O VOSEIO HISPANO-AMERICANO}

O voseio vos-vos, para referir uma só pessoa, é hoje de uso frequente na língua espanhola, não no espanhol europeu, mas um pouco por todos os países da América hispânica, dos quais se destacam a Argentina e o Uruguai pelo seu uso generalizado e por estar presente nos mais diversos contextos linguísticos, sociais e geográficos (BENAVIDES, 2003; CARRICABURO, 1997; CASTEDO, 2013). Nas palavras de Carricaburo (1997, p. 9-11) o voseio coexiste com o tuteio pois ambos expressam familiaridade, informalidade, ou amizade entre os falantes. Por este motivo, os tratamentos recíprocos $t u$ - $t u$ ou vos-vos possuem o mesmo valor discursivo, ou seja, ambos são usados para expressar confiança entre os interlocutores. De acordo com Benavides (2003, p. 619) na Argentina e no Uruguai o voseio vos-vos é de uso comum em todos os estratos sociais, inclusive nas escolas e universidades, enquanto noutros países hispano-americanos o voseio se encontra mais disperso geograficamente e tende a ser associado a meios rurais ou a classes mais baixas. Segundo Casteda (2014, p. 34), o voseo, antes definido como o uso do pronome ou as formas verbais da segunda pessoa do plural com valor de singular que ainda perdura na América, após a colonização da América espanhola, transformou-se num pronome que passou a ter o valor do tú na península. Neste estudo de Casteda, realizado no seio de uma comunidade linguística boliviana, com o objetivo de "descaracterizar a crença de comprovar se restringe-se a uma classe social mais baixa" (p. 34), a autora adianta que o pronome vos coexiste com o tú e que, de certo modo, "brigam por espaço e crescimento em pé de igualdade para referir-se a uma outra pessoa de maneira informal" (p. 34). No estudo de Casteda, verifica-se que ao contrário do voseio do Nordeste Trasmontano cujas convenções de uso parecem evidentes, baseadas sobretudo na diferença etária, no voseio boliviano nem sempre são claras quais as circunstâncias ou qual o interlocutor que deve iniciar a conversação com o pronome vos, precisamente porque disputa os mesmos espaços de tú e até de usted. Sobre esta questão, a autora afirma que:

[...] o grau de instrução também influencia na sua utilização, ou seja, verificamos que as pessoas pertencentes a uma classe social mais baixa o usam com mais naturalidade e rapidez que aquelas de uma classe social mais elevada que, por sua vez, não foge deste mesmo padrão, porém sentem-se mais inibidos para quebrar as primeiras barreiras ao iniciar uma conversação. Observamos que a faixa etária não é fator fundamental no momento de escolher o pronome a ser utilizado para tratar uma segunda pessoa do singular, porém, aliado à escolaridade, verificamos que quanto maior o nível de instrução, maior resistência a escolher o vos em um momento inicial da conversa. (CASTEDO, 2014, p.48)

Através deste excerto pode-se verificar que a faixa etária não é um fator determinante, além de que este voseio é recíproco, reciprocidade essa que por vezes parece causar algum desconforto em alguns interlocutores. $\mathrm{O}$ voseio boliviano parece ser usado com mais naturalidade por pessoas de menor instrução ou de classe social mais baixa, enquanto os indivíduos de maior instrução ou classe mais elevada terão mais contemplações em relação ao seu uso.

Outra característica a destacar de entre os voseios hispano-americanos é a ocorrência simultânea de tuteio pronominal e voseio verbal, como por exemplo, "tu querés" [tu quereis] uma das particularidades do voseio uruguaio e uma forma de tratamento também muito generalizada neste país sul-americano (CARRIBURO, 1997, p. 11). Esta discordância entre o uso do pronome (tú) e a forma verbal correspondente ao pronome (vós) não é incomum quando ocorrem mudanças linguísticas desta natureza. O testemunho de Basto (1932) é disso exemplo quando menciona os equívocos que se cometiam quando o pronome você começou a tomar espaços anteriormente ocupados pelo pronome vós: "Há muita gente que emprega vocês como se fosse vós, com o verbo na $2^{\mathrm{a}}$ pessoa do 
plural - ex.: vocês vindes ou não vindes - é má concordância que todavia se ouve a pessoas não de todo incultas. É devido a empregarem vocês tendo em mente vós." (BASTO, 1932, p. 191).

O voseio hispano-americano, amplamente usado em vários países, tem semelhanças que o aproximam do voseio português do Nordeste Trasmontano, sendo a principal, o fato de se referir a uma só pessoa. É essencialmente por este motivo que este estudo opta pelo termo voseio ao invés de voseamento, sinônimo em Portugal mais relacionado com o uso de vós para mais do que uma pessoa, como são exemplos as obras de Cintra (1995) ou Teyssier (1997). Nos pontos seguintes deste trabalho analisaremos a eventual existência de outras similaridades entre estes voseios.

\section{METODOLOGIA}

A metodologia seguida pelo presente estudo baseia-se na entrevista como instrumento de pesquisa para coletar dados com interação entre pesquisador e informantes. A entrevista possibilita ao pesquisador compreender melhor os aspectos que a sua experiência empírica e os seus conhecimentos teóricos não podem descortinar (FODDY, 1994; GIL, 2008).

Para este trabalho foram entrevistadas dez pessoas divididas em dois grupos segundo a faixa etária com a finalidade de coletar diretamente a informação e discutir as principais ideias e conclusões que se podem retirar da revisão da literatura sobre o tema. As entrevistas tiveram lugar na aldeia de Avelanoso em Agosto de 2019 e foram efetuadas a indivíduos originários da referida localidade. A maioria dos entrevistados habita permanentemente na aldeia, enquanto outros, embora não vivendo em permanência, ali se dirigem com frequência.

Os informantes foram agrupados em categorias de cinco elementos cada, compostas por dois níveis etários: "entre os 30 e os 40 anos" e "entre os 65 e 75 anos". O primeiro grupo (G1) é constituído por quatro indivíduos do sexo masculino e um do sexo feminino que habitam permanentemente na aldeia e que desempenham diferentes profissões ligadas a instituições públicas (polícia, câmara municipal e centro de dia). O segundo grupo (G2) é composto por três indivíduos do sexo feminino e dois do sexo masculino já retirados da vida laboral, mas que desempenharam funções enquanto professores (três), polícias e profissionais de saúde.

Tendo em consideração as teorias de Gil (2008) pode-se considerar que esta pesquisa tem uma dimensão etnográfica por efetuar o estudo de um grupo ou povo através da interação social entre pesquisador e objeto pesquisado, na qual uma das partes pretende obter dados e a outra se apresenta como fonte de informação. Uma vez que os entrevistados não são indivíduos desconhecidos para o pesquisador, tratou-se de uma entrevista informal que permitiu um diálogo mais demorado e aprofundado sobre o tema investigado. As questões, ou tópicos, foram colocadas de forma aberta e respondidas de forma livre e informal, enquanto o entrevistador anotou as declarações e posteriormente organizou as respostas, promovendo uma avaliação global e qualitativa.

Os entrevistados trocaram abertamente as suas opiniões sobre os tópicos e as perguntas seguiram um guião semi-estruturado para dar liberdade aos entrevistados sem fugir muito do tema e recolher "informações intensivas centradas num indivíduo ou pequeno grupo que sem limites de tempo ou com ampla liberdade, expõe os seus pontos de vista" (SOUSA; BAPTISTA, 2000, p. 81). Cada grupo foi entrevistado em conjunto, tendo sido recolhidas por escrito as opiniões individuais dos informantes, mas também as impressões trocadas em modo de mesa-redonda. Embora alguns entrevistados tenham sido mais participativos que outros, salientese que houve concordância quanto à informação e aos argumentos apresentados sobre as temáticas da entrevista.

As entrevistas centraram-se em cinco questões gerais: a utilização ou recorrência do pronome vós dirigido a uma só pessoa; os contextos ou situações de uso do voseio; a reciprocidade ou não do voseio; a existência ou não de formas híbridas - tal como ocorre no contexto hispano-americano; a coexistência de outras formas de tratamento com o voseio. 


\section{RESULTADOS}

No G1 (entre os 30 e os 40 anos) quatro indivíduos revelam não utilizar o pronome vós dirigido a uma só pessoa, ao passo que um dos entrevistados reconhece utilizá-lo, "por vezes", no local onde trabalha (centro de dia ou lar de idosos) para se dirigir a algumas pessoas da aldeia que ali vivem. Este entrevistado explicou que normalmente trata os utentes por você ou o senhor/a senhora + nome, mas que também recorre ao pronome vós para se dirigir às pessoas que são da aldeia (muitos utentes provêm de outras localidades) e com as quais tem mais intimidade porque "cresceu" com essas pessoas e "sempre conviveu" com as mesmas no espaço da aldeia.

Para se dirigirem a pessoas mais velhas, todos os indivíduos disseram utilizar o pronome você como forma de tratamento, incluindo para com os avós, no entanto, três elementos revelaram que também recorrem ao pronome $t u$ se tiverem confiança com essa pessoa, deixando o você para pessoas muito mais velhas ou menos conhecidas. A forma o senhor/a senhora também foi partilhada por três indivíduos, usada com pessoas com as quais “não há uma relação informal”. De assinalar também que dois entrevistados revelaram utilizar a forma tio + nome próprio para pessoas de muita idade com as quais tenham alguma confiança e que consideram um tratamento "mais próximo, familiar ou afetivo", ainda que agora seja "cada vez mais raro" utilizarem-no.

Em relação às formas de tratamento usadas para com os progenitores, estas dividem-se entre tu (3) e você (2) sendo que estes últimos dizem poder utilizar também a mãe/o pai seguidos do verbo na $3^{\text {a }}$ pessoa do singular.

Após serem questionados sobre eventuais mudanças no uso do voseio vós-tu, isto é, se anteriormente usavam esta forma mas a teriam deixado de usar ao longo do tempo, os entrevistados referiram que não deixaram de usar este tipo de voseio porque "nunca o usaram" ou "não se recordam de o terem usado", embora registrem que antigamente era mais frequente ouvirem esta forma de tratamento na aldeia por parte da "geração dos seus pais para com pessoas mais velhas" ou pelos seus próprios "pais a tratarem os avós”.

$\mathrm{Na}$ entrevista com o G2 (entre os 65 e os 75 anos) estabeleceram-se mais comparações entre a recorrência do voseio, e de outras formas de tratamento, no passado e nos tempos de hoje.

Na atualidade, também é cada vez menos frequente esta geração recorrer a este voseio, uma vez que apenas o usam com "uma ou outra" pessoa mais velha com quem tenham confiança. Os entrevistados revelaram que se na infância ou juventude usavam este voseio porque era "a forma de tratamento que todos usavam" e "não se atreveriam" a tratar as pessoas mais velhas de outra forma, agora fazem-no mais como demonstração de "respeito, familiaridade ou estima” do que por convenção ou obrigação. Por exemplo, dois entrevistados desta faixa etária com progenitores ainda vivos dizem tratá-los “umas vezes por vós, outras por vocể, embora confessem "não prestar muita atenção a isso".

Todos os cinco elementos do G2 revelaram que utilizavam, no passado, o pronome vós em contexto familiar para se dirigirem aos pais (ao pai ou à mãe de forma individual), aos tios ou avós, assim como à generalidade das pessoas mais velhas da aldeia com quem tinham proximidade. No seio familiar usavam-se os vocativos vós meu pai/vós minha mãe ou vós meu avô/vós minha avó, de que são exemplo as frases, vós meu pai, vinde cá, vós minha mãe, onde ides? ou vós meu avô, esperai por mim.

Em relação à reciprocidade, todos sublinharam também que este tipo de voseio não era recíproco, ou seja, efetuava-se na forma vós$t u$ pois as pessoas mais velhas respondiam com a segunda pessoa do singular.

Quanto à existência de formas híbridas em termos de concordância verbal, tal como Basto (1932) ou Carriburo (1997) fazem referência, os entrevistados respondem unânime e negativamente: "não ocorria" ou "que eu me recorde não". Fazia-se apenas uso de vós $+2^{a}$ pessoa do plural. No entanto, adiantaram ser comum a errada conjugação de alguns verbos. Por exemplo, no pretérito perfeito do indicativo, em vez de "fizestes, estivestes, dissestes ou comestes" era muito comum as pessoas dizerem "vós fizesteis, estivesteis, dissesteis ou comesteis". Esta incorreção de se adicionar a letra $i$ poderia ser motivada pelo fato de alguns verbos no presente do indicativo (e no pretérito imperfeito - fazíeis, dizíeis ou comíeis) terem i, como:fazeis, dizeis, estais ou comeis. Alguns entrevistados 
registaram ainda a antiga frequência da palavra andivesteis, resultante da aglutinação de dois verbos (andar + estar), um vocábulo gramaticalmente incorreto, mas algo peculiar semanticamente.

Em relação a outras formas de tratamento usadas em concomitância com o voseio, os informantes indicam que em situações de maior formalidade o mais comum seria o senhor/a senhora (seguido da terceira pessoa do singular), como por exemplo, senhor padre, senhora professora ou utilizado para alguém "desconhecido ou vindo de fora". Nas situações informais, para a generalidade das pessoas mais velhas da aldeia, usava-se tio/tia + nome próprio ou alcunha seguido da segunda pessoa do plural. Quanto aos progenitores, além de vós, também eram tratados em algumas circunstâncias por o senhor meu pai/ a senhora minha mãe ou o senhor seu pai/a senhora sua mãe, formas de tratamento à época comuns em Portugal tal como documentado por Basto (1932, p. 193).

\section{AGORA O VÓS SOMOS NÓS}

Aprofundando a discussão ou reflexão acerca dos resultados, pode-se afirmar que o G1, apesar de ter contactado com este tipo de voseio pela boca da geração mais velha, praticamente não fez uso dele. Alguns entrevistados afirmaram que durante a infância recorriam a esta forma pronominal para tratar uma ou outra pessoa com quem tinham mais familiaridade, mas presentemente apenas um dos entrevistados disse usá-lo no seu local de trabalho (centro de dia) para se referir a algumas pessoas que ali vivem e que são da mesma aldeia. $O$ facto de este voseio se fazer ouvir sobretudo no lar de terceira idade da aldeia acaba por ser paradigmático do atual envelhecimento desta forma de tratamento.

O G2 recorre a este voseio esporadicamente para tratar os progenitores ou algumas pessoas de mais idade. Os informantes do G2 (nascidos nas décadas de 40 e 50 do século anterior) afirmam que, ao contrário de hoje, durante a sua infância e juventude este voseio era de uso comum e generalizado nas relações informais. Fora desse contexto, imperava o tratamento nominal senhor/senhora acompanhado da terceira pessoa. Durante a entrevista relatou-se que quando "uma pessoa se casava com alguém de fora" ou "quando vinha uma pessoa de fora mais importante" era tratada por senhor/senhora seguido da terceira pessoa, o que é revelador da estreita familiaridade que este voseio pressupunha. Neste contexto, a deferência associada ao uso do pronome vós evoca também informação significativa sobre a caracterização do interlocutor, nomeadamente a idade (uma vez que pressupõe uma considerável diferença de idades) e a origem (o fato de ser alguém local, da aldeia ou das redondezas, que pertence àquele meio).

Em relação à predominância do pronome você em detrimento de vós, os entrevistados desta geração, indicam os anos 70 e 80 como altura em que se começou a generalizar o uso de você. Devido a mudanças na organização social com "a abertura da aldeia" a novas realidades e com "a influência dos migrantes", ou seja, as pessoas originárias da aldeia que viviam noutros locais do país e que "traziam o você", esta forma de tratamento começou a difundir-se inexoravelmente.

Os entrevistados explicaram que antes disso o tratamento pronominal você não era comum na aldeia, mas uma forma trazida "da cidade”, afirmando um deles que após ir viver para Lisboa é que ouviu pela primeira vez o pronome você. Algumas pessoas que saíam da aldeia para estudar e trabalhar, "quando voltavam já não usavam tanto vós, nem sequer tio ou tia”, mas as formas mais comuns da cidade que eram vistas como "mais finas ou modernas", sinal de que a pessoa era mais "bem-falante e tinha mais educação". Esta invasão do pronome você, lembra as palavras quase centenárias de Cláudio Basto: "Dantes você, assim como vossemecê, evitava-se com pessoas de cerimónia - Você é estrebaria! Agora é moda, é de bom tom, é chic o tratamento de você.” (BASTO, 1932, p. 17).

Sobre estas mudanças linguísticas, uma das entrevistadas contou que uma vez ao regressar da cidade onde estudava (Porto) utilizou a forma nominal Dona $+3^{a}$ pessoa do singular para com uma vizinha e que esta se sentira muito lisonjeada com tal forma de tratamento por considerá-la uma forma "da cidade" interpretada como moderna, refinada ou "chique". O voseio e as formas de tratamento mais tradicionais foram ficando cada vez mais desusadas uma vez que se percebiam as formas de tratamento vindas de fora como sinónimo de "mais educação ou estatuto". O desuso deste voseio acaba assim por estar ligado ao binómio meio rural/meio urbano, mas também a esta dança das formas de tratamento em busca de estatuto e posição social que pautam a história da cultura sociolinguística portuguesa. 
Sobre esta temática os entrevistados referiram ainda o exemplo do mirandês, contando que o mirandês não era falado na cidade de Miranda do Douro - apenas nas aldeias do concelho de Miranda e em algumas do concelho de Vimioso, tal como defende Ferreira (2004) - por ser muitas vezes visto com uma “língua menor, de gente modesta e com menos estudos”. Quando alguém destas aldeias a viver fora regressava para um período de férias e optava por falar português em vez de mirandês, os da terra usavam a expressão "falar fidalgo" para se referirem ao falar português, visto como mais nobre, "moderno ou citadino".

A forma como as próprias pessoas destes meios, à época, viam os seus próprios usos e hábitos linguísticos como algo de somenos, com uma certa inferioridade, ou pelo menos desatualização, em contraponto com as realizações mais modernas ou cultas (a seu ver) que se praticavam noutros meios, também contribui para a abertura e adesão a novos costumes linguísticos. Pode-se afirmar que muitas realizações linguísticas particulares do Nordeste Trasmontano terão começado a mudar significativamente com a abertura das aldeias a novas realidades levadas pelas suas gentes e à forma menorizada como eram interpretados os usos locais em relação aos que chegavam de fora.

Ao longo das últimas décadas a massificação de formas de tratamento como você e a expressão de informalidade com que se procedem as relações sociais, conduziram ao gradual decaimento do voseio vós-tu. A este propósito, um dos informantes do G2 usou a expressão "agora o vós somos nós", aludindo ao fato de serem da atual geração ou faixa etária passível de ser tratada por vós, ainda que agora os jovens os tratem por você e em alguns casos por $t u$, o que, reconhecem, seria absolutamente "impensável há umas décadas". Quando questionados sobre se gostariam de ser tratados por vós, respondem afirmativamente, falando em "honra" ou "bonita tradição".

Os vários séculos de hierarquia, de reverência e de respeito entre diferentes gerações e classes sociais redundaram nas últimas décadas em mudanças socioculturais que alteraram profundamente os cânones das relações interpessoais e das formas de tratamento. A massificação dos pronomes voce e, sobretudo, $t u$, tem desertificado outras formas de tratamento nos mais variados registos e contextos sociais. Nesta perspetiva, podem-se reter as palavras de Cunha e Cintra (2002) quando argumentam que o pronome tu era até há bem pouco tempo, no Português de Portugal, a forma própria de marcar as distâncias de superior para inferior hierárquico, enquanto hoje "tende a ultrapassar os limites da intimidade, propriamente dita, em consonância como uma intenção igualitária ou, simplesmente, aproximativa (CUNHA; CINTRA, 2002, p. 293). Refira-se também Gouveia (2008, p. 97) quando defende que se vivem tempos de "conversacionalização e coloquialização", uma vez que o discurso público é modelado em função das práticas discursivas da vida quotidiana, como é disso exemplo a forma como os jornalistas se referem às figuras de Estado. Esta quotidianização do discurso num sistema de base igualitária onde "os indivíduos não sentem que existam diferenças de poder e de envolvimento entre as pessoas com quem interagem" (p.98) redimensiona e transforma, por sua vez, as interações sociais e a percepção de nós e dos outros enquanto atores sociais.

\section{CONCLUSÕES}

O voseio vós-tu constitui uma forma de tratamento única (e desconhecida) na língua portuguesa. O seu uso circunscreve-se a algumas localidades fronteiriças do Nordeste Trasmontano e tem origens dúbias que alguns autores associam ao português antigo, mas também ao mirandês ou a dialetos asturo-leoneses. A inexistência de reciprocidade, o pronome vós é usado apenas unilateralmente, e o fato de a idade do interlocutor ser um fator determinante no momento de escolher esta forma de tratamento, constituem características singulares e diferenciadoras, por exemplo, do voseio usado no espanhol americano.

Este voseio contém em si uma mistura única de familiaridade e reverência, de intimidade e respeito, de afetuosidade e consideração, de proximidade e distância, enquanto tratamento formal para relações próximas e informais. Como tal, o decair do voseio representa também o esvaecer do tratamento de formalidade dentro da informalidade expresso nas relações familiares e comunitárias em língua portuguesa.

Apesar de todas estas particularidades, encontra-se em acentuado declínio desde as últimas décadas do século passado devido a questões demográficas, sociais e culturais. O ocaso do voseio vós-tu das formas de tratamento do Nordeste, com as suas delimitações 
geográficas e humanas, sugere representar também o ocaso de um determinado tempo e de uma determinada geração. Considerando-se uma língua como uma herança histórica e cultural que cada geração vai transmitindo à seguinte (Sausurre, 1995) é inteligível que existam usos que se percam e outros que se adquiram ao longo do caminho que as sociedades percorrem.

Por hora, cabe ao bós do mirandês manter esta voseada herança nordestina como um dos vários desafios que se apresentam a uma língua minoritária e geograficamente apartada dos grandes centros de decisão. Em fim de ciclo ou de geração, conclui-se que o voseio vós-tu do português do Nordeste Trasmontano é hoje pouco mais do que a reminiscência de um passado na iminência de acabar e contra o qual parece haver pouco a fazer.

\subsection{FUTURAS INVESTIGAÇÕES}

Este estudo pretende também evidenciar a pertinência da realização de investigações no Nordeste Transmontano com maior dimensão que incluam a recolha de material em suporte áudio ou vídeo de forma a reunir e catalogar não só a recorrência e a delimitação geolinguística do voseio vós-tu, mas várias outras realizações de particular valor linguístico e sociocultural que se têm alterado significativamente ao longos das últimas décadas, como as formas de tratamento, os vocativos ou os vocábulos particulares desta região do país. Alguns entrevistados lembraram, por exemplo, a grande quantidade de palavras do castelhano que se utilizavam há décadas quando os povos da raia de ambos os lados interagiam de forma muito estreita, formando comunidades que se relacionavam ativamente em termos sociais, culturais e económicos, devido ao acentuado distanciamento ou isolamento em relação aos respetivos meios urbanos. Segundo os entrevistados, inúmeras palavras importadas ou partilhadas com o outro lado da fronteira para referir ações ou nomear objetos do quotidiano encontram-se também em inexorável descaminho dos falares do Nordeste à medida que findam as gerações que viveram grande parte das suas vidas durante esses tempos de enérgicas interações raianas.

As mudanças nos papéis sociais e profissionais, o contacto com outros registos linguísticos ou a influência dos meios de comunicação, entre outros motivos, resultaram em alterações nas formas de tratamento e na generalidade das particularidades sociolinguísticas das gentes do Nordeste.

\section{REFERÊNCIAS}

BASTO, C. Formas de tratamento em português. Revista Lusitana, Porto, v. xixx, p. 183-202, 1932.

BENAVIDES, C. La distribución del voseo en Hispanoamérica. Hispania, v. 86, n. 3, p. 612-623, 2003.

BIDERMAN, M. T. Formas de tratamento e estruturas sociais. Alfa: Revista de Linguística, v. 18/19, Marília, p. 339-381, 1972-1973.

BROWN, R.; GILMAN A. The pronouns of power and solidarity. In: SEBEOK, T. A. (ed.). Style in Language, Cambridge: Cambridge University Press, 1960. p. 253-276.

CARREIRA, M. H. Modalisation linguistique en situation d'interlocution: proxémique verbale et modalities en portugais. LouvainParis: Peeters, 1997.

CARREIRA, M. H. Cortesia e proxémica: abordagem semântico-pragmática. In: SEARA, I. R. (coord.). Cortesia: olhares e (re)invensões, Lisboa: Chiado, 2014. p. 27-46.

CASTELEIRO, J. M. (dir.). Dicionário da língua portuguesa contemporânea. Lisboa: Editorial Verbo; Academia das Ciências de Lisboa, 2001. 
CARRICABURO, N. Las formas de tratamiento en el español actual. Madrid: Arco Libros, 1997.

CASTEDO, T. Um estudo sociolinguístico sobre o pronome vos em Santa Cruz de la Sierra. Trabalho apresentado ao XVII Congresso Internacional da Associação de Linguística e Filologia da América Latina (ALFAL). 2014. João Pessoa:Universidade Federal da Paraíba, João Pessoa, 2014, p. 33-52. Disponível em: https://mundoalfal.org/CDAnaisXVII/trabalhos/R0290-2.pdf Acesso em: 13 maio 2020.

CUNHA, C.; CINTRA, L. Nova Gramática do português contemporâneo. 17. ed. Lisboa: Edições João Sá da Costa, 2002.

CINTRA, L. Sobre formas de tratamento na língua portuguesa. Lisboa: Livros Horizonte, 1972.

CINTRA, L. Estudos de dialectologia portuguesa. 2. ed. Lisboa: Livraria Sá da Costa Editora, 1995.

ELIZAINCÍN, A. Los estudios sobre la frontera España/Portugal. Enfoque histórico. Revista de Estudios Extremeños, Badajoz, v. lxii, n. 2, p. 607-621, 2006.

FERNANDES, F. P. F.; HENDGES, G. R.Voseo: aspectos e variantes voseantes dentro da hipanoamérica. Idéias, v. 16, p. 31-34, 2002.

FERREIRA, A. Modos de tratamento ne l mirandés de Sendin. El Filandar/O Fiadeiro, v. xiii, Zamora, p. 8-13, 2001.

FERREIRA, A. La Cidade de Miranda de 1 Douro i la lhéngua mirandesa. El filandar/O Fiadeiro, v. xv, Zamora, p. 19-24, 2004.

FERREIRA, M. B. O mirandês e as línguas do noroeste peninsular. Lletres Asturianes, v. lvii, Oviedo, p.7-22, 1995.

FERREIRA, M.B. A situação actual da língua mirandesa e o problema da delimitação histórica dos dialectos asturo-leoneses em Portugal. Revista de Filologia Românica, v. 18, p. 117-136, 2008.

FODDY, W. Como perguntar: teoria e prática da construção de perguntas em entrevistas e questionários. Oeiras: Celta, 1996.

GIL, A. C. Métodos e técnicas de pesquisa social. 6. ed. São Paulo: Atlas, 2008.

GOUVEIA, C. As dimensões da mudança no uso das formas de tratamento em Português Europeu. In: OLIVEIRA, F.; DUARTE, I. M. (org.). O fascínio da Linguagem: Actas do Colóquio de Homenagem a Fernanda Irene Fonseca. Porto: CLUP/FLUP, 2008. p. 91-100.

LUZ, M. Formas de tratamento. Revista Portuguesa de Filologia, v. VII, VIII e IX, Coimbra: 1958.

CASTELEIRO, J. Pronomes pessoais e formas de tratamento. In: CASTELEIRO, J.; PASCOAL, J.; MEIRA, A. (coord.). Nível limiar. Estrasburgo: Conselho da Europa; Lisboa: Instituto de Cultura e Língua Portuguesa, 1988. p. 376-380.

MATEUS, M. H. M. et al. Gramática da língua portuguesa. 5. ed. Lisboa: Editorial Caminho, 2003.

SANTOS, M. J. Os falares transfronteiriços de Trás-os-Montes. Separata da Revista Portuguesa de Filologia, v. xii, t.xiii e xiv, Coimbra: Instituto de Estudos Românicos, 1967.

SAUSSURE, F. Curso de linguística geral. 26. ed. Trad. Antônio Chelini, José Paulo Paes, Izidoro Blikstein. São Paulo: Cultrix, 1995. 
SOUSA, M.; BAPTISTA, C. Como fazer investigação, dissertações, teses e relatórios - Segundo Bolonha. 3.ed. Lisboa: Edições Lidel, 2012.

TEYSSIER, P. A história da língua portuguesa. Trad. Celso Cunha. São Paulo: Martins Fontes, 1997.

\section{() (1) $\circledast$}

Recebido em 24/01/2021. Aceito em 14/02/2021. 